\title{
Application of marine-based gold nanomaterials in cancer ther- apy: A mini-review
}

\author{
Neda Baghban ${ }^{1}$, Arezoo Khoradmehr ${ }^{1}$, Iraj Nabipour ${ }^{1, *}$, Amin Tamadon ${ }^{1, *}$ \\ 1 The Persian Gulf Marine Biotechnology Research Center, The Persian Gulf Biomedical Sciences Research \\ Institute, Bushehr University of Medical Sciences, Bushehr, Iran \\ * Correspondences: Iraj Nabipour: inabipour@gmail.com;Amin Tamadon: amintamaddon@yahoo.com
}

\author{
Authors' email \\ Neda Baghban, neda.baghban@gmail.com \\ Arezoo Khoradmehr, mehrarezoo@gmail.com \\ Iraj Nabipour, inabipour@gmail.com \\ Amin Tamadon, amintamaddon@yahoo.com
}

\begin{abstract}
Cancer is one of the health concerns in modern societies. The application of nanotechnology in medical sciences has created new possibilities for the diagnosis, imaging and the treatment of tumors in humans. The present article reviews the application of marine-based gold nanoparticles in diagnosing and treating cancer. The main data were collected from research article on the application of different marine-based gold nanoparticles in detecting and imaging cancer cells as well as in drug delivery system in treatment of cancer. Chitosan is the most used marine natural compound used to fabricate gold nanocomposites and the most reported application of this type of nano-composites is related to drug delivery system. Despite the excellent anticancer potential of different marine natural products, less studies have been conducted on the use of their compositions with gold nanoparticles in cancer therapy than other materials. Moreover, most reports available in this filed are related to their application as a drug delivery system not anticancer drug. In general, there are still challenges and limitations to the use of nanoparticles in medicine, it is hoped that in the near future nanoparticles will create a dramatic revolution not only in oncology but also in medicine.
\end{abstract}

Keywords: cancer; gold nanoparticles; marine; drug delivery; imaging; detection

\section{Introduction}

Despite progress in detection and treatment of cancers, cancer is still one of the most common causes of death today. According to WHO, cancer caused approximately 10 million deaths in 2020 in worldwide [1] and was the second leading cause of death following heart disease [2,3]. Some carcinogens are physical factors such as ultraviolet radiation, chemical factors such as cancer-inducing chemical compounds, cigarette smoke, unbalanced diet, occupational factors, hereditary factors, hormonal factors, metabolic factors and biological factors, especially some bacteria and viruses [4-9]. The most common types of tumors leading to death worldwide are lung, colon and rectum, liver, stomach, and breast tumors, respectively [10]. Today, the most important treatment for cancer is chemotherapy and radiotherapy [11-13], which in addition to numerous side effects [14,15], also create drug resistance in the patient $[16,17]$. Other disadvantage of common cancer treatment methods is that in these methods, both healthy and cancer cells are affected by the drug and undergo changes, which cause that not enough drug reaches the cancer cells and the excretion of those drugs also increases [18]. Thus, it is essential to enhance the rate of drug injection, which is not economical and is not be possible depending on the general condition and tolerance of the patient. Another important obstacle in treating cancer is its late diagnosis $[19,20]$, which unfortunately causes to have no enough time to treat cancer and 
it mostly ends up with death of the infected person shortly after the diagnosis. Therefore, studies are ongoing on finding effective and non-destructive strategies for early diagnosis of cancer and it is yet needed to discover a suitable drug or carrier of medicine to be used as an effective chemotherapeutic agent.

Nowadays, nanomedicine, the application of nanotechnology in healthcare, has come to the aid of treatment and diagnosis of several diseases [21]. In this context, new strategies for diagnosing and treating cancer have been proposed due to better understanding of tumor biology and advances in cancer nanotechnology [22]. Nanometer-scale particles act in amazing ways as the properties of materials at the nanometer scale change and they exhibit special optical, electronic and structural properties [23-25]. Due to these unique properties, nanoparticles can be used in imaging, diagnosing and treating cancers $[26,27]$. In modern medical science, using these features, nanoparticles are engineered to be able to deliver high doses of cytotoxic drugs to the cancer site while protecting healthy cells from the side effects of cytotoxic drugs [28]. Moreover, to diagnose cancer at an early stage, scientists must be able to detect molecular changes (even if they occur in a small percentage of cells). Meanwhile, the ability of nanostructures to enter cells and analyze them is promising [29]. Among different nano particles, gold nanoparticles (AuNPs) have extensively attracted attentions as a leading nanomaterial for hybrid cancer therapy [30].

In recent years, owing to the side effects of chemotherapy drugs [31,32], people prefer to use natural products to treat cancer [33]. One of these natural resources with high healing properties are plants and living organisms in different depths of the sea. Deep sea has resulted in natural compounds with high therapeutic properties due to conditions such as darkness, lack of oxygen, high pressure and low temperature [34]. The results of scientific studies on medicinal properties of these products are promising for the treating many diseases, including cancer, and are able to reduce the toxicity of other drugs due to their antioxidant properties [35].

This review tries to summarize studies conducted on the application of marine based gold nano composites in cancer cell therapy and suggest some ideas for future studies in this field. For this purpose, advances of gold nanomaterials and marine natural compounds in cancer therapy are briefly described and then, marine based nano gold materials used in cancer therapy are summarized and discussed. Finally, some suggestions are provided for future studies in this field.

\section{Advances of gold nanomaterials in cancer treatment}

Gold nanomaterials have unique properties compared to other metal nanoparticles that have made them suitable for using in cancer nanotechnology (Figure 1). Gold nanomaterials are strongly suitable drug carrier owning to simplicity in their modification with special ligand, drug or protein to bind selectively to cancer cells, and their large capacity to load drug because of the large ratio of surface area to volume. For example, the application of gold nanomaterials in delivery of cisplatin, carboplatin, nedaplatin and oxaliplatin have been reported [36-38]. Owing to their versatile surface chemistry [39], unique optical and surface plasmon resonance (SPR), photoresponsive properties, long body circulation times, selective accumulation at target sites via the enhanced permeability and retention (EPR) effect or modifying surface, great absorption in the near-infrared region, and easy functionalization, they have been greatly used for imaging cancer cells using different techniques such as computerized tomography (CT), photothermal/photoacoustic imaging, and Raman spectroscopy. Gold nanomaterials have applied in radiosensitization to increase efficacy of radiation therapy, which causes effective cancer cells killing. In general, the radiosensitization mechanism is yet unclear, but it can be attributed to enhanced adsorption of photon of high-Z elements and transferring a larger amount of primary ionizing photon energy to cancer cells. The use of gold nanomaterials in inducing hyperthermia $\left(40-45^{\circ} \mathrm{C}\right)$ of tumor has been also reported [40]. Gold nanomaterials are promising gene delivery vehicles, due to their easy surface modification and large specific surface area. Besides abovementioned applications, gold nanomaterials have been used to stabilize other drug carriers and to promote releasing drugs. On the other hand, AuNPs are of 
interest to scientists for in vivo studies because they are non-reactive in biological systems, bio compatible and low toxic. Despite the importance and advances of GNPs in treating cancer, according to https://clinicaltrials.gov/, there have been limited clinical trials on the use of this nanomaterial in cancer therapy.

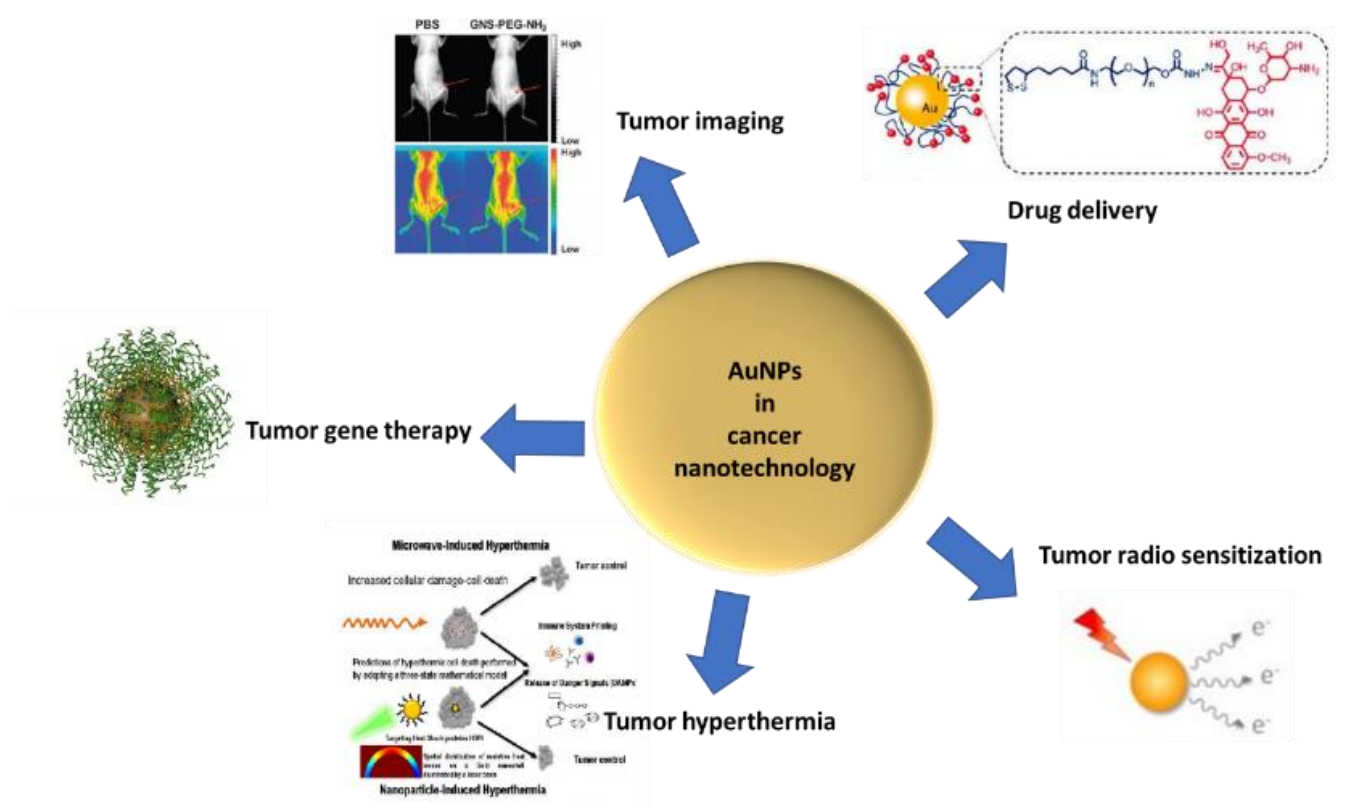

Figure 1. Applications of AuNPs in cancer diagnosis and treatment.

\section{Advances of marine natural products in cancer treatment}

The seas cover $70 \%$ of the earth's surface [41]. The biodiversity of the seas is considerably greater than the land surface and accounts for almost $70 \%$ of all living organisms [42]. The marine environment is considered as a rich source of natural products with wide therapeutic applications [43]. Many bioactive compounds with anti-cancer potential have been extracted from diverse marine organisms such as microalgas [44], sponges [45], mollusks [46], tunicates and other marine organisms. According to various studies, their anti-cancer potential is mainly due to their antioxidant [47] and anti-proliferative [48]. These compounds discovered from marine organisms stimulate cell death by various mechanisms such as apoptosis [49], effect on anti-microtubule [50], angiogenic inhibition [51], antiproliferative [52] and cytotoxic [53]. For example, shark cartilage has been shown to have inhibitory effects on angiogenesis, metastasis, cell adhesion and proteolysis. Oral consumption of shark cartilage dry powder has been widely used as a treatment for cancer [54]. The provision of anti-cancer drugs from marine sources has opened a new horizon for treating various cancers with drug-resistant properties. The future of medicine is from that sea, and the sea will play a major role in the discovery of drugs, especially anti-cancer drugs. Some of these compounds reported during recent year have been listed in Table 1 . There are about 300 completed clinical trials registered on https://clinicaltrials.gov/that 38 of which are related to fish oil. 
Table 1. Some of anti-cancer marine natural products reported over 2021.

\begin{tabular}{|c|c|c|c|}
\hline Compound & Cancer type & Mechanism & $\overline{\text { Ref }}$ \\
\hline $\begin{array}{l}\text { 14-3-3 protein } \\
\text { Hsp70 } \\
\text { Rab3 } \\
\text { Arylsulfatase B } \\
\text { Serine protease }\end{array}$ & $\begin{array}{l}\text { Ovarian can- } \\
\text { cer }\end{array}$ & Anti-proliferative activity & [55] \\
\hline 4H-chromen-4-one & $\begin{array}{l}\text { Pancreatic } \\
\text { cancer } \\
\text { Colon cancer }\end{array}$ & - & [56] \\
\hline $\begin{array}{l}\text { Benzo[g][1]benzopyrano[4,3-b]in- } \\
\text { dol-6(13H)-ones }\end{array}$ & $\begin{array}{l}\text { Cervical can- } \\
\text { cer } \\
\text { Lung cancer } \\
\text { Breast cancer }\end{array}$ & Inhibitory effect & [57] \\
\hline Dieckol & $\begin{array}{l}\text { Pancreatic } \\
\text { cancer }\end{array}$ & Apoptosis and inhibition & [58] \\
\hline $\begin{array}{l}\text { Epiremisporine E } \\
\text { Epiremisporine B }\end{array}$ & Lung cancer & Bcl-2, Bax, and caspase 3 signaling cascade & [59] \\
\hline Fucoxanthin & $\begin{array}{l}\text { Pancreatic } \\
\text { cancer }\end{array}$ & $\begin{array}{l}\text { Up-regulating the expression of integrin } \beta 1, \mathrm{FAK} \text {, } \\
\text { Paxillin, FYN, AKT, and PPAR } \gamma\end{array}$ & [60] \\
\hline MBS 3.2 & $\begin{array}{l}\text { Colorectal } \\
\text { cancer }\end{array}$ & - & [61] \\
\hline $\begin{array}{l}\text { Pyrrospirone F } \\
\text { Chrysophanol } \\
\text { Physcion } \\
\text { Purpuride G }\end{array}$ & Lung cancer & Anti-proliferative activity & [62] \\
\hline Streptoglutarimide $\mathrm{H}$ & Lung cancer & Anti-glioma activity & [63] \\
\hline $\begin{array}{l}\text { The ethanol extract of Aaptos suber- } \\
\text { itoides }\end{array}$ & Breast cancer & $\begin{array}{l}\text { Suppressing Cell Viability, Cell Proliferation and Cell } \\
\text { Migration }\end{array}$ & [64] \\
\hline Tilapia piscidin 4 & $\begin{array}{l}\text { Synovial sar- } \\
\text { coma }\end{array}$ & $\begin{array}{l}\text { Disrupting oxidative status } \\
\text { Promoting mitochondrial hyperpolarization } \\
\text { Causing calcium overload }\end{array}$ & [65] \\
\hline
\end{tabular}

\section{Advances of marine based gold nanocomposites in cancer treatment}

Different types of marine based gold nanocomposites have been fabricated for various purposes. One of main reasons to fabricate GNPs using marine source is related to the interest of scientists to produce economic and eco-friendly materials through green procedures $[66,67]$. In general, chemicals and solvents used in chemical synthesis procedures, have hazardous impacts on the environment and human health [68]. Besides, it is well known that marine natural compounds are rich sources of bioactive materials [69]. Therefore, it is expected that we could design affective drugs for different diseases with the aid of bioactive properties of marine natural compounds and unique properties of GNPs. In this regard, some recent reports on the use of these materials in different areas have been summarized in Table 2. 
Table 2. Different application of marine based nano gold materials.

\begin{tabular}{|c|c|c|}
\hline Material & Application & Ref. \\
\hline (PABA-SAL)@AuNPs & Biomedical applications & {$[70]$} \\
\hline APTMS-CS-AuNPs & Antimicrobial & {$[71]$} \\
\hline AuNPs/CS-GR-IL-Fc cry/SPCE & Measuring prostate-specific antigen & {$[72]$} \\
\hline AuNPs/Lac/Alg & Detection of Fe(III) & [73] \\
\hline CS-AuNPs & Biomedical devices & {$[74]$} \\
\hline CS-AuNPs & Raman spectroscopy & [75] \\
\hline CS-AuNPs & Biosensor & [76] \\
\hline CS-AuNPs & Antimicrobial & [77] \\
\hline CS-AuNPs & siRNA delivery and silencing & [78] \\
\hline CS-AuNPs & Detection of uric acid & [79] \\
\hline CS-AuNPs & Nanocatalyst & {$[80]$} \\
\hline CS-AuNPs & Biomemristor & {$[81]$} \\
\hline CS-AuNPs & Antibacterial & {$[82]$} \\
\hline CS-TiNPGF & Determination of acetaminophen & [83] \\
\hline Fe3O4@Alg-Au NPs & Nanocatalyst & {$[84]$} \\
\hline GNPs-chitosan-horseradish peroxidase & Biosensor & {$[85]$} \\
\hline Ibuprofen lysinate-CS-AuNPs & Anti-inflammatory & {$[86]$} \\
\hline Nano gold-marine algae sodium-Alg & Electric transport & {$[87]$} \\
\hline PAA/CS/Au nanocomposite hydrogel & Antimicrobial activity & {$[88]$} \\
\hline SA-AuNPs & Detection of ascorbic acid & [89] \\
\hline Sea urchin-PVP-AuNPs & Transient immune activation & {$[90]$} \\
\hline SUGNPs & SERS platform & [91] \\
\hline ZnSA-AuAMP hydrogel & Controllable regulation of nanozyme activity & [92] \\
\hline
\end{tabular}

Abbreviations: (PABA-SAL)@AuNPs: Gold nanoparticles/polyaniline boronic acid/sodium alginate aqueous nanocomposite, APTMS: 3-aminopropyltrimethoxysilane, AuAMP: 5'-monophosphate capped Au nanoclusters, AuNPs/Lac/Alg: gold nanoparticles on novel nanocomposite lactose/alginate, CS-GR-IL-Fc: Chitosan, graphene, ionic liquid and ferrocene, NPGF: Nano-porous gold film, PAA/CS/Au: Polyacrylic acid/chitosan/gold, PVP: Polyvinylpyrrolidone, SA-AuNPs: Reduced/stabilized gold nanoparticles, SERS: Surface Enhanced Raman scattering, SPCE: Screen-printed carbon electrode, SUGNPs: Sea urchin-like gold nanoparticles.

Despite marine based gold nanocomposites have been widely investigated for diverse medicinal properties [93], to the best of our knowledge, limited investigates have been reported on the use of marine based gold nanocomposites in cancer therapy. Table 3 shows a list of marine based nano gold materials used for different purposes in cancer nanotechnology. This list was provided through searching key words "gold" and "cancer" and "marine, alga, micro alga or sponge" and "nano, nanoparticle, nanocomposite or nanomaterial" at Google Scholar database. According to Table 3, despite the wide variety of marine natural compounds and their great potential as anticancer drug, their composites with gold mostly limited to chitosan-gold NPs in which chitosan plays role as stabilizer not anticancer drug. The role of gold in these compounds is mostly as a drug carrier. 
Table 3. Application of marine based gold nanomaterials in cancer nanotechnology.

\begin{tabular}{|c|c|c|c|c|c|}
\hline Type of cancer & Nano-composite & $\begin{array}{l}\text { Spe- } \\
\text { cies }\end{array}$ & $\begin{array}{l}\text { In } \\
\text { vivo/In } \\
\text { vitro }\end{array}$ & Application & Ref. \\
\hline Brain cancer & Apt-Dox-CS-Au-5FU NPs & Human & In vitro & Anticancer & [94] \\
\hline $\begin{array}{l}\text { Breast cancer } \\
\text { Colon cancers }\end{array}$ & Actinomycetes-AuNPs & Human & In vitro & Anticancer & [95] \\
\hline $\begin{array}{l}\text { Breast cancer } \\
\text { Cervical cancer } \\
\text { Lung cancer }\end{array}$ & CMC-AuNPs & Human & In vitro & Drug delivery & [96] \\
\hline Breast cancer & CS-GNPs & Human & In vitro & Drug delivery & [97] \\
\hline Breast cancer & CS-GNPs-DOX & Human & In vitro & Drug delivery & {$[98]$} \\
\hline Breast cancer & CS-g-PNVCL nanofibers-G-GSNPs & Human & In vitro & Drug delivery & [99] \\
\hline $\begin{array}{l}\text { Breast cancer } \\
\text { Lung cancer }\end{array}$ & DOX-Apts-CS-AuNPs & Mouse & In vivo & Drug delivery & [100] \\
\hline Breast cancer & FA-CS-GNP-5-FU & Human & In vitro & Drug delivery & [101] \\
\hline $\begin{array}{l}\text { Breast cancer } \\
\text { Hepatic cancer } \\
\text { Kidney cancer }\end{array}$ & FCG5-FU-NPs & Human & In vitro & Drug delivery & [102] \\
\hline Breast cancer & G1 & Human & In vitro & Drug delivery & [103] \\
\hline Breast cancer & GC-AuNPs & Human & In vitro & PAI & [104] \\
\hline Breast cancer & $\mathrm{J}-\mathrm{Au}-\mathrm{CS}$ & Mouse & In vivo & Imaging & [105] \\
\hline Breast cancer & PTX-COS-AuNPs & Human & In vitro & $\begin{array}{l}\text { Drug delivery } \\
\text { PAI }\end{array}$ & [106] \\
\hline Breast cancer & SPION@Au-CS-DOX-FA NPs & Human & In vitro & Anticancer & [107] \\
\hline $\begin{array}{l}\text { Cervical cance } \\
\text { Colon cancer } \\
\text { Liver cancer }\end{array}$ & Folate HTCC-AuNPs & Human & In vitro & Drug delivery & [108] \\
\hline Cervical cancer & Au@CS-PMPC NPs & Human & In vitro & $\begin{array}{l}\text { Drug release } \\
\text { Fluorescence im- } \\
\text { aging }\end{array}$ & [109] \\
\hline Cervical cancer & CS-GNPs & Human & In vitro & Drug delivery & [110] \\
\hline Cervical cancer & DOX-AuNPs-CMC & Human & In vitro & Drug delivery & [111] \\
\hline Colon cancer & Alginate hydrogel- GNPs-cisplatin & Mouse & in vivo & Drug delivery & [112] \\
\hline Colon cancer & alginate-AuNPs & Mouse & in vivo & Drug delivery & [113] \\
\hline Colon cancer & As-AuNPs & Human & In vitro & Anticancer & [114] \\
\hline Colon cancer & EPI-CAO-AuNPs & Human & In vitro & Drug delivery & [115] \\
\hline Colon cancer & Vibrio alginolyticus-AuNPs & Human & In vitro & Anticancer & {$[66]$} \\
\hline $\begin{array}{l}\text { Gastric cancer } \\
\text { Lung cancer }\end{array}$ & marine bacterium GNPs & Human & In vitro & Drug delivery & [116] \\
\hline Liver cancer & Chitosan-bee venom-GNPs & Rat & in vivo & Drug delivery & [117] \\
\hline Liver cancer & Chitosan-GNPs & Human & In vitro & Gene therapy & [118] \\
\hline Liver cancer & Macroalgae GNPs & Human & In vitro & Drug delivery & [119] \\
\hline
\end{tabular}


Lung cancer

Prostate cancer Cs/PVA/AuNPs

Human In vitro Drug delivery

[120]

Abbreviations: As-AuNPs: A. spicifera-mediated gold nanoparticles, CMC-AuNPs: N,O-carboxymethyl chitosan effectively stabilized gold nanoparticles, Cs/PVA/AuNPs: Chitosan/Poly (Vinyl Alcohol) Blend Doped with Gold Nanoparticles, DOX-Apts-CS-AuNPs: Doxorubicin and aptamer against Forkhead box M1 chitosanGold nanoparticles, DOX-AuNPs-CMC: Doxorubicin immobilized on gold nanoparticles capped with carboxymethyl chitosan, FA-CS GNP-5-FU: Folic Acid Conjugated Conjugated-Chitosan Functionalized Gold Nanoparticles, FCG5-FU-NPs: Folate linked counterpart 5-fluorouracil encapsulated chitosan functionalized gold nanoparticles, G1: Chitosan-functionalized gold nanoparticles, GC: glycol chitosan, GC-AuNPs glycol-chitosan-coated gold nanoparticles, HTCC: N-(2-hydroxy)propyl-3-trimethylammonium Chitosan Chloride, PAI: Photoacoustic imaging, PMPC: benzaldehyde-terminated poly[(2-methacryloyloxy) ethyl phosphorylcholine], PTX-COS AuNPs: Paclitaxel-loaded chitosan oligosaccharide-stabilized gold nanoparticles, TCA: Taurocholic acid.

\section{Conclusion and future outlook}

The current review highlighted advances of GNPs, marine natural products and marine based gold nanomaterials in different aspects of cancer therapy. GNPs have unique properties making them good candidate for using in biomedical areas specially in cancer nanotechnology. The use of these nanoparticles has been reported in drug delivery, imaging, radio sensitization, hyperthermia and gene therapy for cancer. Despite the great interest of scientists to use of this nanoparticle for medical purpose, there has been no registered clinical report on the use of it in cancer therapy according to https://clinicaltrials.gov/. There are many available reports on the anticancer activity of a variety of marine natural products and numerous clinical reports on the use of it in cancer therapy have been registered in https://clinicaltrials.gov/. Considering the advances of both GNPs and marine natural products in cancer therapy, it is expected combining them results in more effective drugs and delivery systems, which are also imaging contrast agents. Reviewing studies performed on marine based gold nanocomposites showed these compounds mostly contain chitosan as a stabilizer of GNPs and are used as drug delivery systems. Accordingly, it is greatly recommended to conduct studies on synthesizing these compounds as anticancer drugs and imaging contrast agents. Moreover, most of the studies have been conducted under in vitro condition, designing in vivo studies using these materials is greatly recommend considering the biocompatibility, low toxicity and bioinertness of these materials.

Author Contributions: Conceptualization, N.B. and A.T.; methodology, N.B. and A.T.; investigation, N.B. and A.K.; writing-original draft preparation, N.B.; writing-review and editing, A.K., I.N. and A.T.; supervision, I.N. and A.T.; project administration, I.N. and A.T.; funding acquisition, I.N. and N.B. All authors have read and agreed to the published version of the manuscript.

Funding: This study has been financially supported by Allame Tabatabaei Post-Doc Fellowship Program from Iran's National Elites Foundation (INEF). The funder had no role in study design, data collection and analysis, decision to publish, or preparation of the manuscript.

Acknowledgments: This study has been financially supported by Allame Tabatabaei Post-Doc Fellowship Program from Iran's National Elites Foundation (INEF). The funder had no role in study design, data collection and analysis, decision to publish, or preparation of the manuscript.

Conflicts of Interest: The authors declare no conflict of interest.

\section{References}

1. Alam, A.; Rampes, S.; Patel, S.; Hana, Z.; Ma, D. Anesthetics or anesthetic techniques and cancer surgical outcomes: A possible link. Korean Journal of Anesthesiology 2021. 
2. Pilleron, S.; Soto - Perez - de - Celis, E.; Vignat, J.; Ferlay, J.; Soerjomataram, I.; Bray, F.; Sarfati, D. Estimated global cancer incidence in the oldest adults in 2018 and projections to 2050. International journal of cancer 2021, 148, 601-608.

3. Lees, B.; Hampton, J.M.; Trentham-Dietz, A.; Newcomb, P.; Spencer, R. A population-based study of causes of death after endometrial cancer according to major risk factors. Gynecologic Oncology 2021, 160, 655-659.

4. Srinivas, N.; Malla, R.R.; Kumar, K.S.; Sailesh, A.R. Environmental carcinogens and their impact on female-specific cancers. In A Theranostic and Precision Medicine Approach for Female-Specific Cancers, Elsevier: 2021; pp. 249-262.

5. $\quad$ van der Sloot, K.W.; Tiems, J.L.; Visschedijk, M.C.; Festen, E.A.; van Dullemen, H.M.; Weersma, R.K.; Kats-Ugurlu, G.; Dijkstra, G. Cigarette smoke increases risk for colorectal neoplasia in inflammatory bowel disease. Clinical Gastroenterology and Hepatology 2021.

6. Burns, C.J.; Juberg, D.R. Cancer and occupational exposure to pesticides: an umbrella review. International Archives of Occupational and Environmental Health 2021, 1-13.

7. Mori, G.; Pasca, M.R. Gut Microbial Signatures in Sporadic and Hereditary Colorectal Cancer. International Journal of Molecular Sciences 2021, 22, 1312.

8. Kim, G.; Bahl, M. Assessing risk of breast cancer: a review of risk prediction models. Journal of Breast Imaging 2021.

9. Parsonnet, J. Bacterial infection as a cause of cancer. Environ Health Perspect 1995, 103 Suppl 8, 263-268, doi:10.1289/ehp.95103s8263.

10. Sung, H.; Ferlay, J.; Siegel, R.L.; Laversanne, M.; Soerjomataram, I.; Jemal, A.; Bray, F. Global cancer statistics 2020: GLOBOCAN estimates of incidence and mortality worldwide for 36 cancers in 185 countries. CA: A Cancer Journal for Clinicians n/a, doi:https://doi.org/10.3322/caac.21660.

11. Takakusagi, Y.; Yoshida, D.; Kusano, Y.; Kano, K.; Anno, W.; Tsuchida, K.; Mizoguchi, N.; Serizawa, I.; Katoh, H.; Imura, K. Dosimetric Comparison Between Carbon-ion Radiotherapy and Photon Radiotherapy for Stage I Esophageal Cancer. In Vivo 2021, 35, 447-452.

12. $\mathrm{Al}$ - Jubouri, M.B.A.; Isam, S.R.; Hussein, S.M.; Machuca - Contreras, F. Recitation of quran and music to reduce chemotherapy - induced anxiety among adult patients with cancer: A clinical trial. Nursing Open 2021.

13. Wongkhieo, S.; Numdee, K.; Lam, E.W.; Choowongkomon, K.; Kongsema, M.; Khongkow, M. Liposomal Thiostrepton Formulation and Its Effect on Breast Cancer Growth Inhibition. Journal of Pharmaceutical Sciences 2021.

14. Borges da Silva, E.; Brayner Cavalcanti, M.; Ferreira Da Silva, C.S.; de Salazar e Fernandes, T.; Azevedo Melo, J.; Lucena, L.; Maciel Netto, A.; Amaral, A. Micronucleus assay for predicting side effects of radiotherapy for cervical cancer. Biotechnic $\mathcal{E}$ Histochemistry 2021, 96, 60-66.

15. Sutton, E.; Lane, J.; Davis, M.; Walsh, E.; Neal, D.; Hamdy, F.; Mason, M.; Staffurth, J.; Martin, R.; Metcalfe, C. Men's experiences of radiotherapy treatment for localized prostate cancer and its long-term treatment side effects: a longitudinal qualitative study. Cancer Causes $\mathcal{E}$ Control 2021, 32, 261-269.

16. Deng, P.; Sun, M.; Zhao, W.-Y.; Hou, B.; Li, K.; Zhang, T.; Gu, F. Circular RNA circVAPA promotes chemotherapy drug resistance in gastric cancer progression by regulating miR-125b-5p/STAT3 axis. World Journal of Gastroenterology 2021, 27, 487.

17. Li, Y.; Wang, Z.; Ajani, J.A.; Song, S. Drug resistance and Cancer stem cells. Cell Communication and Signaling 2021, 19, 1-11.

18. Miller, K.D.; Siegel, R.L.; Lin, C.C.; Mariotto, A.B.; Kramer, J.L.; Rowland, J.H.; Stein, K.D.; Alteri, R.; Jemal, A. Cancer treatment and survivorship statistics, 2016. CA: a cancer journal for clinicians 2016, 66, 271-289.

19. Lei, F.; Xi, X.; Rachagani, S.; Seshacharyulu, P.; Talmon, G.A.; Ponnusamy, M.P.; Batra, S.K.; Bronich, T.K. Nanoscale platform for delivery of active IRINOX to combat pancreatic cancer. Journal of Controlled Release 2021, 330, $1229-1243$.

20. Manier, K.K.; Maibach, H.I. Skin Cancer Knowledge, Awareness, and Perception. Ethnic Skin and Hair and Other Cultural Considerations 2021, 43-53.

21. Kim, B.Y.; Rutka, J.T.; Chan, W.C. Nanomedicine. New England Journal of Medicine 2010, 363, $2434-2443$.

22. Ferrari, M. Cancer nanotechnology: opportunities and challenges. Nature reviews cancer 2005, 5, 161-171. 
23. Antonietti, M.; Göltner, C. Superstructures of functional colloids: chemistry on the nanometer scale. Angewandte Chemie International Edition in English 1997, 36, 910-928.

24. Bazzi, R.; Brenier, A.; Perriat, P.; Tillement, O. Optical properties of neodymium oxides at the nanometer scale. Journal of luminescence 2005, 113, 161-167.

25. Mintmire, J.; White, C. Electronic and structural properties of carbon nanotubes. Carbon 1995, 33, 893-902.

26. Wang, X.; Yang, L.; Chen, Z.; Shin, D.M. Application of nanotechnology in cancer therapy and imaging. CA: a cancer journal for clinicians 2008, 58, 97-110.

27. Cryer, A.M.; Thorley, A.J. Nanotechnology in the diagnosis and treatment of lung cancer. Pharmacology E therapeutics 2019, 198, 189-205.

28. Li, Z.; Tan, S.; Li, S.; Shen, Q.; Wang, K. Cancer drug delivery in the nano era: An overview and perspectives. Oncology reports 2017, 38, 611-624.

29. Chaturvedi, V.K.; Singh, A.; Singh, V.K.; Singh, M.P. Cancer nanotechnology: a new revolution for cancer diagnosis and therapy. Current drug metabolism 2019, 20, 416-429.

30. Cai, W.; Gao, T.; Hong, H.; Sun, J. Applications of gold nanoparticles in cancer nanotechnology. Nanotechnology, science and applications 2008, 1, 17.

31. MacDonald, V. Chemotherapy: managing side effects and safe handling. The Canadian Veterinary Journal $2009,50,665$.

32. Aslam, M.S.; Naveed, S.; Ahmed, A.; Abbas, Z.; Gull, I.; Athar, M.A. Side effects of chemotherapy in cancer patients and evaluation of patients opinion about starvation based differential chemotherapy. Journal of Cancer Therapy 2014, 2014.

33. Mann, J. Natural products in cancer chemotherapy: past, present and future. Nature Reviews Cancer 2002, 2, $143-148$.

34. Sarfaraj, H.M.; Sheeba, F.; Saba, A.; Khan, M. Marine natural products: A lead for Anti-cancer. 2012.

35. Khalifa, S.A.; Elias, N.; Farag, M.A.; Chen, L.; Saeed, A.; Hegazy, M.-E.F.; Moustafa, M.S.; El-Wahed, A.; Al-Mousawi, S.M.; Musharraf, S.G. Marine natural products: A source of novel anticancer drugs. Marine drugs 2019, 17, 491.

36. Min, Y.; Mao, C.; Xu, D.; Wang, J.; Liu, Y. Gold nanorods for platinum based prodrug delivery. Chemical communications 2010, 46, 8424-8426.

Brown, S.D.; Nativo, P.; Smith, J.-A.; Stirling, D.; Edwards, P.R.; Venugopal, B.; Flint, D.J.; Plumb, J.A.; Graham, D.; Wheate, N.J. Gold nanoparticles for the improved anticancer drug delivery of the active component of oxaliplatin. Journal of the American Chemical Society 2010, 132, 4678-4684.

38. Qi, S.-S.; Sun, J.-H.; Yu, H.-H.; Yu, S.-Q. Co-delivery nanoparticles of anti-cancer drugs for improving chemotherapy efficacy. Drug Delivery 2017, 24, 1909-1926, doi:10.1080/10717544.2017.1410256.

39. Rastgoo-Lahrood, A.; Martsinovich, N.; Lischka, M.; Eichhorn, J.; Szabelski, P.; Nieckarz, D.; Strunskus, T.; Das, K.; Schmittel, M.; Heckl, W.M. From Au-Thiolate Chains to Thioether Sierpinski Triangles: The Versatile Surface Chemistry of 1, 3, 5-Tris (4-mercaptophenyl) benzene on Au (111). Acs Nano 2016, 10, 10901-10911.

40. Chatterjee, D.K.; Diagaradjane, P.; Krishnan, S. Nanoparticle-mediated hyperthermia in cancer therapy. Ther Deliv 2011, 2, 1001-1014, doi:10.4155/tde.11.72.

41. Irigoien, X.; Huisman, J.; Harris, R.P. Global biodiversity patterns of marine phytoplankton and zooplankton. Nature 2004, 429, 863-867.

De Vries, D.J.; Beart, P.M. Fishing for drugs from the sea: status and strategies. Trends in pharmacological sciences 1995, 16, 275-279.

43. Newman, D.J.; Cragg, G.M. Marine natural products and related compounds in clinical and advanced preclinical trials. Journal of natural products 2004, 67, 1216-1238.

44. Martínez Andrade, K.A.; Lauritano, C.; Romano, G.; Ianora, A. Marine Microalgae with Anti-Cancer Properties. Marine Drugs 2018, 16, 165.

45. Kim, G.-Y.; Kim, W.-J.; Choi, Y.H. Pectenotoxin-2 from marine sponges: A potential anti-cancer agent-A review. Marine drugs 2011, 9, 2176-2187. 
46. Flores, M.; Ammon, M.; Forteza, I. Isolation of Marine Mollusk-Associated Bacteria for use as Anti Bacterial and Anti-Cancer Leads. 2011.

47. Takamatsu, S.; Hodges, T.W.; Rajbhandari, I.; Gerwick, W.H.; Hamann, M.T.; Nagle, D.G. Marine Natural Products as Novel Antioxidant Prototypes. Journal of Natural Products 2003, 66, 605-608, doi:10.1021/np0204038.

48. Palanisamy, S.K.; Arumugam, V.; Rajendran, S.; Ramadoss, A.; Nachimuthu, S.; Peter D, M.; Sundaresan, U. Chemical diversity and anti-proliferative activity of marine algae. Natural Product Research 2019, 33, 2120-2124, doi:10.1080/14786419.2018.1488701.

49. Ganesan, P.; Noda, K.; Manabe, Y.; Ohkubo, T.; Tanaka, Y.; Maoka, T.; Sugawara, T.; Hirata, T. Siphonaxanthin, a marine carotenoid from green algae, effectively induces apoptosis in human leukemia (HL-60) cells. Biochimica et Biophysica Acta (BBA) - General Subjects 2011, 1810, 497-503, doi:https://doi.org/10.1016/j.bbagen.2011.02.008.

50. Chen, S.-M.; Meng, L.-H.; Ding, J. New microtubule-inhibiting anticancer agents. Expert Opinion on Investigational Drugs 2010, 19, 329-343, doi:10.1517/13543780903571631.

51. Shin, H.J.; Kim, T.S.; Lee, H.-S.; Park, J.Y.; Choi, I.-K.; Kwon, H.J. Streptopyrrolidine, an angiogenesis inhibitor from a marine-derived Streptomyces sp. KORDI-3973. Phytochemistry 2008, 69, 2363-2366, doi:https://doi.org/10.1016/j.phytochem.2008.05.020.

52. Simon-Levert, A.; Menniti, C.; Soulère, L.; Genevière, A.-M.; Barthomeuf, C.; Banaigs, B.; Witczak, A. Marine Natural Meroterpenes: Synthesis and Antiproliferative Activity. Marine Drugs 2010, 8, 347-358.

53. Mayer, A.M.S.; Gustafson, K.R. Marine pharmacology in 2003-2004: Anti-tumour and cytotoxic compounds. European Journal of Cancer 2006, 42, 2241-2270, doi:https://doi.org/10.1016/j.ejca.2006.05.019.

54. Shahrokhi, S.; Zuhair, M.; Mohagheghi, M.; Ghazanfari, T.; Ebtekar, M. Shark cartilage modulates immune responses in stage III breast cancer patients. International Journal of Hematology-Oncology and Stem Cell Research 2009, 21-28.

55. Rodrigo, A.P.; Mendes, V.M.; Manadas, B.; Grosso, A.R.; Alves de Matos, A.P.; Baptista, P.V.; Costa, P.M.; Fernandes, A.R. Specific Antiproliferative Properties of Proteinaceous Toxin Secretions from the Marine Annelid Eulalia sp. onto Ovarian Cancer Cells. Marine Drugs 2021, 19, 31.

56. Kurt-Kızıldoğan, A.; Akarsu, N.; Otur, Ç.; Kivrak, A.; Aslan-Ertas, N.; Arslan, S.; Mutlu, D.; Konus, M.; Yılmaz, C.; Cetin, D. A Novel 4H-Chromen-4-One Derivative from Marine Streptomyces ovatisporus S4702T as Potential Antibacterial and AntiCancer Agent. Anti-cancer Agents in Medicinal Chemistry 2021.

57. Ishibashi, F.; Fukuda, T.; Zha, S.; Hashirano, A.; Hirao, S.; Iwao, M. Concise synthesis and in vitro anticancer activity of benzo [g][1] benzopyrano [4, 3-b] indol-6 (13 H)-ones (BBPIs), topoisomerase I inhibitors based on the marine alkaloid lamellarin. Bioscience, Biotechnology, and Biochemistry 2021, 85, 181-191.

58. Xu, J.W.; Yan, Y.; Wang, L.; Wu, D.; Ye, N.K.; Chen, S.H.; Li, F. Marine bioactive compound dieckol induces apoptosis and inhibits the growth of human pancreatic cancer cells PANC - 1. Journal of Biochemical and Molecular Toxicology 2021, 35, e22648.

59. Chu, Y.-C.; Chang, C.-H.; Liao, H.-R.; Cheng, M.-J.; Wu, M.-D.; Fu, S.-L.; Chen, J.-J. Rare Chromone Derivatives from the Marine-Derived Penicillium citrinum with Anti-Cancer and Anti-Inflammatory Activities. Marine Drugs 2021, 19, 25.

60. Terasaki, M.; Takahashi, S.; Nishimura, R.; Kubota, A.; Kojima, H.; Ohta, T.; Hamada, J.; Kuramitsu, Y.; Maeda, H.; Miyashita, K. A Marine Carotenoid of Fucoxanthinol Accelerates the Growth of Human Pancreatic Cancer PANC-1 Cells. Nutrition and Cancer 2021, 1-16.

61. Lim, S.M.; Agatonovic-Kustrin, S.; Lim, F.T.; Ramasamy, K. High-performance thin layer chromatography-based phytochemical and bioactivity characterisation of anticancer endophytic fungal extracts derived from marine plants. Journal of pharmaceutical and biomedical analysis 2021, 193, 113702.

62. Ge, H.; Shi, M.; Ma, M.; Lian, X.-Y.; Zhang, Z. Evaluation of the antiproliferative activity of 106 marine microbial metabolites against human lung cancer cells and potential antiproliferative mechanism of purpuride G. Bioorganic E Medicinal Chemistry Letters 2021, 127915. 
63. Ge, H.; Zhang, D.; Shi, M.; Lian, X.; Zhang, Z. Antiproliferative Activity and Potential Mechanism of Marine-Sourced Streptoglutarimide H against Lung Cancer Cells. Marine drugs 2021, 19, 79.

64. Bashari, M.H.; Arsydinilhuda, F.Z.; Ilhamsyah, R.S.; Nugrahani, A.D.; Nurdin, R.A.; Kartika, A.; Huda, F.; Abdurahman, M.; Putri, T.; Qomarilla, N. The Ethanol Extract of Marine Sponge Aaptos suberitoides Suppress Cell Viability, Cell Proliferation and Cell Migration in HER2-Positive Breast Cancer Cell Line. Asian Pacific Journal of Cancer Prevention 2021, 22, 25-32.

65. Su, B.-C.; Hung, G.-Y.; Tu, Y.-C.; Yeh, W.-C.; Lin, M.-C.; Chen, J.-Y. Marine Antimicrobial Peptide TP4 Exerts Anticancer Effects on Human Synovial Sarcoma Cells via Calcium Overload, Reactive Oxygen Species Production and Mitochondrial Hyperpolarization. Marine Drugs 2021, 19, 93.

66. Shunmugam, R.; Balusamy, S.R.; Kumar, V.; Menon, S.; Lakshmi, T.; Perumalsamy, H. Biosynthesis of gold nanoparticles using marine microbe (Vibrio alginolyticus) and its anticancer and antioxidant analysis. Journal of King Saud UniversityScience 2021, 33, 101260.

67. AlNadhari, S.; Al-Enazi, N.M.; Alshehrei, F.; Ameen, F. A review on biogenic synthesis of metal nanoparticles using marine algae and its applications. Environmental Research 2021, 194, 110672.

68. Vidal, R.; Alberola-Borràs, J.-A.; Habisreutinger, S.N.; Gimeno-Molina, J.-L.; Moore, D.T.; Schloemer, T.H.; Mora-Seró, I.; Berry, J.J.; Luther, J.M. Assessing health and environmental impacts of solvents for producing perovskite solar cells. Nature Sustainability 2021, 4, 277-285.

69. Nweze, J.A.; Mbaoji, F.N.; Li, Y.-M.; Yang, L.-Y.; Huang, S.-S.; Chigor, V.N.; Eze, E.A.; Pan, L.-X.; Zhang, T.; Yang, D.-F. Potentials of marine natural products against malaria, leishmaniasis, and trypanosomiasis parasites: a review of recent articles. Infectious Diseases of Poverty 2021, 10, 1-19.

70. Jayeoye, T.J.; Eze, F.N.; Sudarshan, S.; Olatunde, O.O.; Benjakul, S.; Rujiralai, T. Synthesis of gold nanoparticles/polyaniline boronic acid/sodium alginate aqueous nanocomposite based on chemical oxidative polymerization for biological applications. International Journal of Biological Macromolecules 2021.

71. Virgili, A.H.; Laranja, D.C.; Malheiros, P.S.; Pereira, M.B.; Costa, T.M.; de Menezes, E.W. Nanocomposite film with antimicrobial activity based on gold nanoparticles, chitosan and aminopropylsilane. Surface and Coatings Technology 2021, 127086.

72. Choosang, J.; Khumngern, S.; Thavarungkul, P.; Kanatharana, P.; Numnuam, A. An ultrasensitive label-free electrochemical immunosensor based on 3D porous chitosan-graphene-ionic liquid-ferrocene nanocomposite cryogel decorated with gold nanoparticles for prostate-specific antigen. Talanta 2021, 224, 121787.

73. Ho, T.T.-T.; Dang, C.-H.; Huynh, T.K.-C.; Hoang, T.K.-D.; Nguyen, T.-D. In situ synthesis of gold nanoparticles on novel nanocomposite lactose/alginate: Recyclable catalysis and colorimetric detection of Fe (III). Carbohydrate Polymers 2021, 251, 116998.

74. Tenório, F.S.; do Amaral Montanheiro, T.L.; dos Santos, A.M.I.; dos Santos Silva, M.; Lemes, A.P.; Tada, D.B. Chitosan hydrogel covalently crosslinked by gold nanoparticle: Eliminating the use of toxic crosslinkers. Journal of Applied Polymer Science 2021, 138, 49819.

75. Puente, C.; Sánchez-Domínguez, M.; Brosseau, C.L.; López, I. Silver-chitosan and gold-chitosan substrates for surfaceenhanced Raman spectroscopy (SERS): Effect of nanoparticle morphology on SERS performance. Materials Chemistry and Physics 2021, 260, 124107.

76. Motia, S.; Bouchikhi, B.; El Bari, N. An electrochemical molecularly imprinted sensor based on chitosan capped with gold nanoparticles and its application for highly sensitive butylated hydroxyanisole analysis in foodstuff products. Talanta 2021, 223, 121689.

77. Islam, S.; Bakhtiar, H.; Alshoaibi, A.; Haider, Z.; Yaacob, S.N.S.; Riaz, S.; Naseem, S. Structural and antimicrobial response of chitosan capped gold nanostructures employing two different synthetic routes. Optical Materials 2021, $112,110741$. 
78. Shaabani, E.; Sharifiaghdam, M.; De Keersmaecker, H.; De Rycke, R.; De Smedt, S.; Faridi-Majidi, R.; Braeckmans, K.; Fraire, J.C. Layer by Layer Assembled Chitosan-Coated Gold Nanoparticles for Enhanced siRNA Delivery and Silencing. International Journal of Molecular Sciences 2021, 22, 831.

79. Li, F.; He, T.; Wu, S.; Peng, Z.; Qiu, P.; Tang, X. Visual and colorimetric detection of uric acid in human serum and urine using chitosan stabilized gold nanoparticles. Microchemical Journal 2021, 164, 105987.

80. Bulut, O.; Yilmaz, M.D. Catalytic evaluation of biocompatible chitosan-stabilized gold nanoparticles on oxidation of morin. Carbohydrate Polymers 2021, 258, 117699.

81. Raeis-Hosseini, N.; Rho, J. Solution-Processed Flexible Biomemristor Based on Gold-Decorated Chitosan. ACS Applied Materials \& Interfaces 2021, 13, 5445-5450.

82. Hussein, M.A.M.; Grinholc, M.; Dena, A.S.A.; El-Sherbiny, I.M.; Megahed, M. Boosting the antibacterial activity of chitosangold nanoparticles against antibiotic-resistant bacteria by Punicagranatum L. extract. Carbohydrate Polymers 2021, 256, 117498.

83. Sadeghi, M.; Shabani-Nooshabadi, M. High sensitive titanium/chitosan-coated nanoporous gold film electrode for electrochemical determination of acetaminophen in the presence of piroxicam. Progress in Organic Coatings 2021, 151, 106100.

84. Ghorbani-Vaghei, R.; Veisi, H.; Aliani, M.H.; Mohammadi, P.; Karmakar, B. Alginate modified magnetic nanoparticles to immobilization of gold nanoparticles as an efficient magnetic nanocatalyst for reduction of 4-nitrophenol in water. Journal of Molecular Liquids 2021, 327, 114868.

85. Zhao, X.; Wei, L.; Pang, G.; Xie, J. A novel GABABR1a receptor electrochemical biosensor based on gold nanoparticles chitosan - horseradish peroxidase. Electroanalysis.

86. Jaber, N.; Al-Akayleh, F.; Abdel-Rahem, R.A.; Al-Remawi, M. Characterization ex vivo skin permeation and pharmacological studies of ibuprofen lysinate-chitosan-gold nanoparticles. Journal of Drug Delivery Science and Technology 2021, 62, 102399.

87. Barone, C.; Bertoldo, M.; Capelli, R.; Dinelli, F.; Maccagnani, P.; Martucciello, N.; Mauro, C.; Pagano, S. Electric Transport in Gold-Covered Sodium-Alginate Free-Standing Foils. Nanomaterials 2021, 11, 565.

88. Biswal, A.; Sethy, P.K.; Swain, S.K. Change in Orientation of Polyacrylic Acid and Chitosan Networks by Imprintment of Gold Nanoparticles. Polymer-Plastics Technology and Materials 2021, 60, 182-194.

89. Jayeoye, T.J.; Sirimahachai, U.; Rujiralai, T. Sensitive colorimetric detection of ascorbic acid based on seed mediated growth of sodium alginate reduced/stabilized gold nanoparticles. Carbohydrate Polymers 2021, 255, 117376.

90. Alijagic, A.; Barbero, F.; Gaglio, D.; Napodano, E.; Benada, O.; Kofroňová, O.; Puntes, V.F.; Bastús, N.G.; Pinsino, A. Gold nanoparticles coated with polyvinylpyrrolidone and sea urchin extracellular molecules induce transient immune activation. Journal of Hazardous Materials 2021, 402, 123793.

91. Sang, Y.; Chen, X.; Zhang, L.; Li, D.; Xu, H. Electrospun polymeric nanofiber decorated with sea urchin-like gold nanoparticles as an efficient and stable SERS platform. Journal of Colloid and Interface Science 2021, 590, 125-133.

92. Liu, L.; Jiang, H.; Wang, X. Alkaline phosphatase-responsive Zn2+ double-triggered nucleotide capped gold nanoclusters/alginate hydrogel with recyclable nanozyme capability. Biosensors and Bioelectronics 2021, $173,112786$.

93. Nejati, K.; Dadashpour, M.; Gharibi, T.; Mellatyar, H.; Akbarzadeh, A. Biomedical Applications of Functionalized Gold Nanoparticles: A Review. Journal of Cluster Science, 1-16.

94. Sathiyaseelan, A.; Saravanakumar, K.; Mariadoss, A.V.A.; Wang, M.-H. pH-controlled nucleolin targeted release of dual drug from chitosan-gold based aptamer functionalized nano drug delivery system for improved glioblastoma treatment. Carbohydrate Polymers 2021, 262, 117907, doi:https://doi.org/10.1016/j.carbpol.2021.117907.

95. M Hamed, M.; S Abdelftah, L. Biosynthesis of gold nanoparticles using marine Streptomyces griseus isolate (M8) and evaluating its antimicrobial and anticancer activity. Egyptian Journal of Aquatic Biology and Fisheries 2019, $23,173-184$.

96. Chokradjaroen, C.; Rujiravanit, R.; Theeramunkong, S.; Saito, N. Effect of electrical discharge plasma on cytotoxicity against cancer cells of N, O-carboxymethyl chitosan-stabilized gold nanoparticles. Carbohydrate polymers 2020, $237,116162$. 
97. Kalaivani, R.; Maruthupandy, M.; Muneeswaran, T.; Singh, M.; Sureshkumar, S.; Anand, M.; Ramakritinan, C.; Quero, F.; Kumaraguru, A. Chitosan mediated gold nanoparticles against pathogenic bacteria, fungal strains and MCF-7 cancer cells. International journal of biological macromolecules 2020, 146, 560-568.

98. Fathy, M.M.; Mohamed, F.S.; Elbialy, N.; Elshemey, W.M. Multifunctional Chitosan-Capped Gold Nanoparticles for enhanced cancer chemo-radiotherapy: An invitro study. Physica Medica 2018, 48, 76-83.

99. Banihashem, S.; Nikpour Nezhati, M.; Panahi, H.A.; Shakeri-Zadeh, A. Synthesis of novel chitosan-g-PNVCL nanofibers coated with gold-gold sulfide nanoparticles for controlled release of cisplatin and treatment of MCF-7 breast cancer. International Journal of Polymeric Materials and Polymeric Biomaterials 2020, 69, 1197-1208.

100. Khademi, Z.; Lavaee, P.; Ramezani, M.; Alibolandi, M.; Abnous, K.; Taghdisi, S.M. Co-delivery of doxorubicin and aptamer against Forkhead box M1 using chitosan-gold nanoparticles coated with nucleolin aptamer for synergistic treatment of cancer cells. Carbohydrate Polymers 2020, 248, 116735.

101. Akinyelu, J.; Singh, M. Folic Acid-Conjugated Chitosan Functionalized Gold Nanoparticles for Targeted Delivery of 5Fluorouracil in Breast Cancer. In Proceedings of Proc. 3rd World Congress Rec. Adv. Nanotechnol.

102. Akinyelu, J.; Singh, M. Folate-tagged chitosan-functionalized gold nanoparticles for enhanced delivery of 5-fluorouracil to cancer cells. Applied Nanoscience 2019, 9, 7-17.

103. Bandyopadhyay, A.; Roy, B.; Shaw, P.; Mondal, P.; Mondal, M.K.; Chowdhury, P.; Bhattacharya, S.; Chattopadhyay, A. Chitosan-gold nanoparticles trigger apoptosis in human breast cancer cells in vitro. The Nucleus 2020, 1-14.

104. Sun, I.-C.; Ahn, C.-H.; Kim, K.; Emelianov, S. Photoacoustic imaging of cancer cells with glycol-chitosan-coated gold nanoparticles as contrast agents. Journal of biomedical optics 2019, 24, 121903.

105. Dai, X.; Zhao, X.; Liu, Y.; Chen, B.; Ding, X.; Zhao, N.; Xu, F.J. Controlled Synthesis and Surface Engineering of Janus Chitosan - Gold Nanoparticles for Photoacoustic Imaging - Guided Synergistic Gene/Photothermal Therapy. Small 2021, 2006004.

106. Manivasagan, P.; Bharathiraja, S.; Bui, N.Q.; Lim, I.G.; Oh, J. Paclitaxel-loaded chitosan oligosaccharide-stabilized gold nanoparticles as novel agents for drug delivery and photoacoustic imaging of cancer cells. International journal of pharmaceutics 2016, 511, 367-379.

107. Al-Musawi, S.; Albukhaty, S.; Al-Karagoly, H.; Almalki, F. Design and Synthesis of Multi-Functional Superparamagnetic Core-Gold Shell Nanoparticles Coated with Chitosan and Folate for Targeted Antitumor Therapy. Nanomaterials 2021, 11, 32.

108. Yen, H.-j.; Young, Y.-a.; Tsai, T.-n.; Cheng, K.-m.; Chen, X.-a.; Chen, Y.-c.; Chen, C.-c.; Young, J.-j. Positively charged gold nanoparticles capped with folate quaternary chitosan: Synthesis, cytotoxicity, and uptake by cancer cells. Carbohydrate polymers 2018, 183, 140-150.

109. Ma, K.; Cheng, Y.; Wei, X.; Chen, D.; Zhao, X.; Jia, P. Gold embedded chitosan nanoparticles with cell membrane mimetic polymer coating for $\mathrm{pH}$-sensitive controlled drug release and cellular fluorescence imaging. Journal of Biomaterials Applications 2021, 35, 857-868.

110. Horo, H.; Bhattacharyya, S.; Mandal, B.; Kundu, L.M. Synthesis of functionalized silk-coated chitosan-gold nanoparticles and microparticles for target-directed delivery of antitumor agents. Carbohydrate Polymers 2021, 258, 117659.

111. Madhusudhan, A.; Reddy, G.B.; Venkatesham, M.; Veerabhadram, G.; Kumar, D.A.; Natarajan, S.; Yang, M.-Y.; Hu, A.; Singh, S.S. Efficient pH dependent drug delivery to target cancer cells by gold nanoparticles capped with carboxymethyl chitosan. International journal of molecular sciences 2014, 15, 8216-8234.

112. Mirrahimi, M.; Beik, J.; Mirrahimi, M.; Alamzadeh, Z.; Teymouri, S.; Mahabadi, V.P.; Eslahi, N.; Tazehmahalleh, F.E.; Ghaznavi, H.; Shakeri-Zadeh, A. Triple combination of heat, drug and radiation using alginate hydrogel co-loaded with gold nanoparticles and cisplatin for locally synergistic cancer therapy. International journal of biological macromolecules 2020, $158,617-626$. 
113. Mirrahimi, M.; Abed, Z.; Beik, J.; Shiri, I.; Dezfuli, A.S.; Mahabadi, V.P.; Kamrava, S.K.; Ghaznavi, H.; Shakeri-Zadeh, A. A thermo-responsive alginate nanogel platform co-loaded with gold nanoparticles and cisplatin for combined cancer chemophotothermal therapy. Pharmacological research 2019, 143, 178-185.

114. Babu, B.; Palanisamy, S.; Vinosha, M.; Anjali, R.; Kumar, P.; Pandi, B.; Tabarsa, M.; You, S.; Prabhu, N.M. Bioengineered gold nanoparticles from marine seaweed Acanthophora spicifera for pharmaceutical uses: antioxidant, antibacterial, and anticancer activities. Bioprocess and Biosystems Engineering 2020, 43, 2231-2242.

115. Chen, X.; Han, W.; Zhao, X.; Tang, W.; Wang, F. Epirubicin-loaded marine carrageenan oligosaccharide capped gold nanoparticle system for $\mathrm{pH}$-triggered anticancer drug release. Scientific reports 2019, 9, 1-10.

116. Patil, M.P.; Kang, M.-j.; Niyonizigiye, I.; Singh, A.; Kim, J.-O.; Seo, Y.B.; Kim, G.-D. Extracellular synthesis of gold nanoparticles using the marine bacterium Paracoccus haeundaensis BC74171T and evaluation of their antioxidant activity and antiproliferative effect on normal and cancer cell lines. Colloids and Surfaces B: Biointerfaces 2019, 183, 110455.

117. Dydykina, V.; Zotova, J.; Mochalova, A.; Smirnova, L.; Koryagin, A. The Effect of a Nanostructured Chitosan-bee VenomGold Nanoparticle system on Free Radical Process Activity, blood system Adaptation, and Tumor Growth in Rats with Transplanted Cancer PC-1. Современные технологии в медицине 2015, 7.

118. Akinyelu, J.; Oladimeji, O.; Singh, M. Lactobionic acid-chitosan functionalised gold-coated poly (lactide-co-glycolide) nanoparticles for hepatocyte targeted gene delivery. Advances in Natural Sciences: Nanoscience and Nanotechnology 2021, 11, 045017.

119. Singh, M.; Saurav, K.; Majouga, A.; Kumari, M.; Kumar, M.; Manikandan, S.; Kumaraguru, A. The cytotoxicity and cellular stress by temperature - fabricated polyshaped gold nanoparticles using marine macroalgae, Padina gymnospora. Biotechnology and applied biochemistry 2015, 62, 424-432.

120. Abaza, A.; Hegazy, E.; Mahmoud, G.A.; Elsheikh, B. Characterization and antitumor activity of chitosan/poly (vinyl alcohol) blend doped with gold and silver nanoparticles in treatment of prostatic cancer model. J Pharm Pharmacol 2018, 2018, 659667. 